\title{
RESAPAN BUATAN, SOLUSI MENGATASI
PROBLEMA AIR
}

Suhadi Purwantara

\begin{abstract}
Abstrak
Air secara kuantitas menjadi bermasalah ketika jumlahnya lebih, atau kurang. Kelebihan air dapat berdampak pada penggenangan, sedangkan kekurangan air berakibat pada terbatasnya suplai air untuk kecukupan kebutuhan air. Yang pertama berkaitan dengan bahaya banjir, dan yang kedua berkaitan dengan bahaya kekeringan. Banyak penelitian para pakar di dunia menyimpulkan bahwa solusi mengurangi dua masalah tersebut, banjir dan kekeringan, adalah dengan pembuatan resapan buatan. Tulisan ini menyajikan berbagai masalah banjir dan kekeringan hasil penelitian di berbagai belahan benua tentang pentingnya resapan buatan.
\end{abstract}

Kata kunci: air tanah, banjir, resapan buatan

\section{Pendahuluan}

Problema air hingga kini masih menjadi masalah yang selalu mengikuti perjalanan hidup manusia. Air adalah salah satu di antara empat unsur pokok. Anaxagoras dan Empedcoles, filusuf-filusuf yang hidup pada masa Yunani kuno, memberikan pernyataan bahwa ada empat elemen dasar atau unsur pokok di dunia ini, yaitu udara, air, tanah, dan api. Manusia tidakdapat hidup tanpa udara. Dalam hitungan menit, manusia akan mati bila tidak mendapatkan udara yang mengandung oksigen. Tidak perlu waktu seminggu manusia juga akan mengakhiri hidup bila tidak mendapatkan air untuk minum. Andai saja tidak ada tanah, maka tidak ada media untuk tumbuh dan berkembangnya tumbuhan. Tidak ada tumbuhan berarti meniadakan bahan pangan nabati, sekaligus mempersempit ruang gerak manusia memperoleh energi kehidupan.

Air di suatu waktu dan wilayah dapat merupakan masalah karena jumlahnya atau kuantitasnya, namun juga suatu ketika karena kualitas juga menjadi masalah utama. Kuantitas air yang berlebihan maupun kekurangan mengancam kehidupan manusia. Banjir menjadi masalah yang utama di berbagai wilayah di bumi ini. Namun demikian, kekeringan juga menjadi masalah di berbagai belahan dunia. Banjir besar yang sering melanda kota-kota besar dunia menjadi masalah serius. Bangkok, Jakarta, Semarang, Surabaya adalah kota-kota besar di Asia Tenggara yang sering dilanda banjir. Di Semarang, banjir bahkan sempat menggenangi stasiun kereta api Tawang hingga setinggi $12 \mathrm{~cm}$. Walaupun hanya $12 \mathrm{~cm}$ untuk jalur rel sangat berbahaya dilewati, karena dapat menyebabkan korsleting dan kebakaran pada sistem elektronik yang ada didekat roda kereta api (Tribun Jateng, 24 Februari). Banjir tidak hanya dapat melumpuhkan 
lalulintas jalan raya, jalan kereta api, tetapi bahkan juga bandar udara. Bandara Ahmad Yani Semarang selama satu hari lumpuh tidak ada penerbangan karena banjir, padahal seharusnya ada 22 kali landing dan 22 kali take-off (Tempo Focus, 25 Februari). Keadaaan demikian tidak saja di Indonesia saja tetapi di negara-negara maju juga mengalami. Misalnya LaGuardia Airport dan JFK Joins Newark Airport New York, belum lama ini karena adanya banjir besar dalam sehari bandara tidak berfungsi ( Blomberg News, 30/10/2012), USA Today, 29 Oktober 2012)

Banjir menjadi bahaya (hazard), bila manusia tidak bijak menyikapi. Banjir dapat menjadi bencana (disaster), dan bahkan dapat menjadi malapetaka (catrastope) apabila manusia sudak tidak peduli lagi dengan lingkungan. Ketidakpedulian lingkungan dapat mengganggu ekositem. Perilaku sebagian kecil masyarakat menebang hutan besar-besaran di wilayah hulu untuk diubah menjadi wilayah pertanian dan atau permukiman jelas akan berakibat pada terganggunya ekosistem. Hutan di wilayah pegunungan yang semestinya berguna sebagai peresap air hujan ke dalam tanah sudah tidak lagi berfungsi. Air hujan akhirnya lebih banyak menjadi air limpaan (run-off), dan hanya sedikit yang meresap dalam tanah untuk menyuplai air tanah. Dua masalah muncul, yaitu bertambahnya air limpasan, dan berkurangnya air imbuhan (recharge water) air tanah.

Pembangunan kawasan puncak yang tidak pernah memperhatikan lingkungan bahkan telah menyebabkan banjir di kawasan itu (Republik on Line, 26 Januari 2013). Padahal untuk meminimalisir dampak bencana dapat dibuat cara alternatif pengganti, yaitu dengan membuat ruang-ruang resapan air, maka akan mengurangi banjir bandang dan tetap terjaganya imbuhan air tanah sehingga cadangan air tanah tidak berkurang.

Berkurangnya cadangan air tanah telah menjadi masalah di berbagai wilayah. Semakin tingginya pengambilan air tanah berakibat pada penurunan permukaan air tanah. Contohnya di Bandung permukaan air tanah semaakin turun. Menurut Harnandi dan Wawan Herawan (2009) Kebutuhan air di Bandung mencapai 46,6 juta $\mathrm{m}^{3}$ pada tahun 2000, sedangkan pada tahun 2005 naik menjadi 51,4 juta $\mathrm{m}^{3}$. Tahun 2000 hingga 2006 terjadi penurunan permukaan air tanah setiap tahun di akuifer menengah sebesar 0,11 hingga 12,03 meter, sedangkan di akuifer dalam sebesar 0,16 hingga 2,61 meter. Demikian pula di Yogyakarta. Di Kota Yogyakarta, permukaan sumur air tanah semakin turun (Seputar Indonesia, 28 September 2012). Permukaan air tanah di DIY setiap tahun turun $30 \mathrm{Cm}$ (DPU, 2011). Banyak wilayah yang semestinya berfungsi sebagai wilayah resapan air hujan telah alih fungsi menjadi bangunan hasil budaya manusia, seperti permukiman penduduk, gedung perhotelan, jalan beraspal atau pengerasan (paving) di sejumlah wilayah. Contohnya di Sleman, perluasan pekarangan per tahun mengalami peningkatan $0,16 \%$, sedangkan lahan sawah mengalami penyusutan 0,19\% (RKPD Sleman, 2012).Penduduk di Yogyakarta pada sensus tahun 1971 tercatat hanya 
2.488.544 jiwa, pada tahun 2010 jumlahnya mencapai 3.457 .491 jiwa, sehingga ada kenaikan $40 \%$.

Bertambahnya jumlah penduduk berakibat pada pertambahan penggunaan air tanah. Hasil penelitian DPU bekerjasama dengan Perumahan dan Energi Sumberdaya Mineral Propinsi DIY dengan PT. Cipta Ekapurna Engineering Consultant (CEEC) pada tahun 2011 menunjukkan bahwa di wilayah-wilayah padat penduduk permukaan air tanah cenderung menurun.

Teoritis, ilmuwan telah banyak melontarkan saran kepada pemerintah maupun masyarakat pada umumnya, namun pada tingkat pelaksanaan, pemerintah masih kesulitan koordinasi. Belum ada koordinasi yang baik antar pemerintah daerah dan juga masyarakat. Barangkali perlu puluhan kali bahkan ratusan kali para pakar hidrologi melontarkan saran tentang pentingnya menjaga lingkungan dengan resapan air buatan (artificial recharge).

\section{Kajian Air tanah}

Knapp (1978), Todd (2006), Kiyotoka Mori (1978), Chay Asdak (2007), Charles R. Coble (1987) menggambarkan siklus air atau siklus hidrologi yang hampir sama. Siklus hidrologi ada yang pendek, ada yang dengan perjalanan panjang. Udara yang sebenarnya mengandung uap air yang naik ke angkasa akan menjadi dingin. Hal itu mengikuti gradien suhu, semakin naik suhu udara semakin dingin pada lapisan atmosfer paling bawah, troposfer. Pada ketinggian tertentu, menyebabkan kelembapan relatif udara bertambah. Keadaan dingin menyebabkan udara tidak mampu menahan uap air. Pada ketinggian tertentu udara akan menjadi jenuh, sehingga terjadi proses kondensasi, atau pengembunan di mana uap air yang dikandung oleh udara tersebut menjadi titik-titik air. Arus udara naik menahan titik-titik air, sehingga titik-titik air tersebut melayang-layang di udara. Kumpulan titik-titik air di dalam udara disebut awan. Ketinggian di mana uap air berkondensasi disebut batas tinggi kondensasi. Batas ketinggian di daerah tropis adalah 1600 meter di atas permukaan laut. Jika awan sangat padat maka titik-titik air bergabung satu dengan yang lain sehingga menjadi tetesan air dan akan jatuh kembali ke bumi menjadi hujan. Curah hujan adalah banyaknya air hujan yang jatuh ke permukaan bumi.

Air hujan yang jatuh di permukaan bumi sebagian membasahi vegetasi, sebagian meresap pada pori-pori tanah (infiltrasi), dilanjutkan meresap masuk dalam tubuh air tanah (perkolasi), sebagian menggenang, sebagian menjadi aliran limpasan (run-off) masuk sungai, mengalir ke telaga, danau, laut, dan sebagian menguap. Intinya air terus bergerak, berputar tidak pernah berhenti, termasuk juga air tanah. Air tanah yang ada pada akuifer, baik akuifer bebas, akuifer tertekan, akuifer bertengger, maupun semi akuifer terus mengalami pergerakan walaupun tidak secepat aliran air permukaan. 
Pola aliran air tanah regional (Regional flow patterns ) sebenarnya terbagi menjadi tiga sistem aliran (Todd dan Mays, 2005: 115-116). Ketiga sistem aliran tersebut adalah aliran lokal, aliran medium, dan aliran regional. Sistem aliran lokal (Region of local system of groundwater flow) berarti bahwa air tanah hanya memiliki waktu tinggal (residence time) sebentar, yaitu dalam hitungan puluhan hari hingga bulanan akan muncul sebagai mata air. Keadaan itu biasanya terjadi di wilayah hulu, atau bagian puncak sebelah bawah. Atau terjadi pada air tanah dangkal yang selalu diambil untuk keperluan penduduk dengan cara pemompaan. Aliran medium (Region of intermediate system of groundwater flow) berarti residence time dapat mencapai tahunan hingga dasawarsa sampai aakhirnya muncul sebagai mataair, sedangkan aliran regional (Region of regional system of groundwater flow) memiliki residence time ratusan hingga ribuan tahun yang tetap tersimpan sebagai air tanah dalam.

\section{Resapan Air Tanah}

Hujan yang jatuh di permukaan bumi sebagian meresap dalam tanah menjadi infiltrasi dilanjutkan perkolasi. Media resapan air hujan dapat alami dan buatan. Media resapan alami dapat berupa lahan hutan, lahan gundul, lahan berumput, lahan sawah, lahan pekarangan, dan lain sebagainya. Media resapan buatan dapat berupa sumur resapan air hujan (dangkal), sumur resapan air dalam, maupun genangan buatan seperti waduk, maupun situ buatan. Resapan air tanah ada yang porus, sangat permeabel, ada yang sulit meloloskan air, sehingga infiltrasi berjalan sangat lambat.

Resapan buatan bertujuan antara lain agar air tanah sebagai sumberdaya kehidupan tetap terjaga, menghambat penurunan permukaan air tanah, mengurangi penurunan atau penenggelaman lahan. Berbagai metode pembuatan resapan buatan antara lain dengan pembuatan kubangan, ataupun cekungan (jawa: jogangan) di permukaan tanah, parit, sumur resapan, selokan, penggenangan, maupun pengairan/irigasi. Berbagai metode dengan berbagai formula pernah diterapkan di berbagai Negara di Los Angeles, Arizona Amerika Serikat, Israel, hingga Australia dan hasilnya sangat memuaskan (Todd dan Mays, 2005: 547-556).

Lain lagi dengan Fetter (1988: 459-460) mengemukakan bahwa resapan buatan yang efektif adalah dengan cara pembangunan bendungan sehingga banyak air dapat meresap masuk dalam tubuh air tanah. Masalahnya adalah pada adanya penyumbatan (clogging) pada kubangankubangan buatan. Penyumbatan dapat disebabkan oleh adanya sedimentasi, lempung, pertumbuhan bakteri, maupun pemadataan oleh karena adanya pemompaan air.

Chay Asdak (2007: 228-231) memaknai infiltrasi sebagai suatu proses masuknya air yang pada umumnya adalah air hujan, ke dalam tanah, yang dilanjutkan dengan perkolasi, yang merupakan kelanjutan aliran air masuk dalam tanah ke tubuh air tanah. Infiltrasi terjadi karena adaanya tarikaan 
gaya gravitasi daan gaya kapiler tanah. Laju air infiltrasi yang dipengaruhi gaya gravitasi dibatasi oleh besarnya diameter pori-pori. Mekanisme infiltrasi melibatkan tiga proses yang tidak saling memengaruhi, yaitu: proses masuknya air hujan melalui permukaaan air tanah, tertampungnya air hujan di dalam tanah, dan proses mengalirnya air ke tempat lain baik ke samping,ke bawah, maupun ke atas. Besarnya laju infiltrasi ditentukan oleh jumlah aair yang tersedia di permukaan, sifat permukaan tanah, dan kemampuan tanah untuk mengosongkan air di atas permukaan tanah.

Ada tiga cara pengukuran infiltrasi menurut Knapp (1978) dalam Asdak (2007: 231-232), yaitu:

1. Menentukan beda volume air hujan buatan dengan volume air larian pada percobaan laboratorium menggunakan simulasi hujan buatan.

2. Menggunakan alat infiltrometer

3. Teknik pemisahan hidrograf aliran dari data aliran air hujan.

Selanjutnya dijelaskan bahwa pengukuran infiltrasi menggunakan infiltrometer, Asdak mengutip Dune Leopold (1978), adalah tidak tepat. Hal itu karena laju infiltrasi terukur bisa lebih besar 2 hingga 10 kali laju infiltrasi yang sesungguhnya.

Resapan air menjadi trending topic research di berbagai wilayah dunia. Beberapa hasil penelitian berikut cukup menarik untuk dikaji.

1. Pliakas, et all. (2005), meneliti model resapan buatan yang dilakukan di Yunani, di salah satu wilayah yang dikenal dengan dataran Xanthi. Penelitian ini barangkali lebih tepat disebut sebagai hasil uji penerapan perhitungan aritmatik, yaitu suatu cara yang disebut dengan MODFLOW. Ada model-model lain selain MODFLOW, yaitu MOC, AQUAMOD, INFOME dan lain-lain. Kasus yang terjadi di wilayah Xanthi itu bermula dari tahun 1994 ketika Departemen Pertanian di negara setempat membuat projek resapan buatan dengan memanfaatkan dasar sungai lama (old stream bed), di dekat Sungai Kosynthos wilayah Polysitos. Di wilayah penelitian, secara geologis, ada tiga formasi geologis. Bagian paling atas dengan ketebalan berkisar antara 8 hingga 80 meter berupa lempung pasiran(clayey sand) dengan permeabilitas rendah, di bawahnya berupa kerikil pasir (gravel sand) dengan tebal 10-70 meter yang cukup permeabel, dan di bawahnya berupa lempung debuan atau lumpur liat (clay silt) yang tentu relatif impermeabel.Wilayah penelitian merupakan bekas sungai dengan luas $16,4 \mathrm{~km} 2$. Untuk mengairi wilayah bekas sungai dibangun selokan selebar satu meter sedalam dua meter sepanjang 1600 meter. Panjang bekas sungai lama yang dijadikan wilayah resapan adalah 7,68 km, lebih pendek dari yang sebenarnya (dulu), $12 \mathrm{~km}$. Pada percobaan pertama, tahun 1994 dilakukan selama Maret hingga Mei, 89 hari, tahun berikutnya (1995) 107 hari, 1996 selama 91 hari, 1997 selama 101 hari dengan debit rerata $150 \mathrm{~m}^{3}$ per jam. 
Selanjutnya setiap tahun dialirkan air selama tiga bulan dengan debit yang sama dengan sebelumnya. MODFLOW menyajikan perhitungan matematis yang disajikan dalam tabel-tabel. Hasil penelitian juga dilengkapi dengan grafik dan peta. Tabel menunjukkan besaran debit inflow dari resapan alami (natural recharge), resapan buatan (artificial recharge), kembalian air irigasi (irrigation return), dan aliran air permukaan (lateral inflow). Grafik menyajikan fluktuasi permukaaan air tanah, dan peta wilayah pengaliran sungai, serta wilayah penelitian. Hasil analisis selanjutnya disimpulkan bahwa dengan menggunakan MODFLOW di wilayah studi, yaitu di Polysitos Xanthi, Yunani, proyek resapan buatan dikategorikan memuaskan dan dapat diandalkan. Hal itu tampak setelah dibandingkan dengan daerah lain, muka pziometrik air tanah tidak sefluktuatif daerah lain.

2. Nayak, Purna Cet all; (2006), dalam sebuah studi penelitian yang meneliti potensi teknik suatu jaringan buatan, bertujuan meramalkan fluktuasi muka air tanah dalam akuifer bebas pada suatu wilayah pesisir di India. Metode penelitiannya dengan berdasarkan pada perhitungan statistik dari sejumlah seri data yang ada. Hasil penelitian menunjukkan bahwa prediksi model yang cukup akurat sesuai dengan perhitungan statistik. Secara umum, hasil menunjukkan bahwa model mampu meramalkan tingkat ketinggian muka air tanah hingga empat bulan ke depan.

3. Disertasi dengan judul "Model Pengelolaan Ruang Terbuka Hijau Sebagai Daerah Resapan Di Wilayah DKI Jakarta" oleh Dwi Dinariana, IPB, 2011, bertujuan mengkaji keberadaan Ruang Terbuka Hijau (RTH), menyusun peta alokasi RTH potensial sebagai daerah resapan, menyusun Model Pengelolaan RTH sebagai Daerah Resapan, menyusun skenario kecukupan air tanah yang diperlukan dalam pengelolaan RTH, dan merumuskan arahan kebijakan pengelolaan RTH sebagai daerah resapan air di wilayah DKI Jakarta. Luas keberadaan RTH (penggunaan lahan) ditentukan dengan menggunakan data spasial Interpretasi Citra Satelit Landsat. Dalam penelitian ini model yang digunakan adalah model dinamik-spasial. Tahapan penelitian yang dilakukan yaitu, pertama, pengkajian keberadaan RTH yang ada dan kemampuannya dalam memenuhi kebutuhan air tanah domestik dan persentase kecukupannya dalam memenuhi air tanah domestik. Kedua, penyusunan peta alokasi RTH potensial sebagai daerah resapan dengan analisis terhadap laju resapan, curah hujan, tingkat kepadatan penduduk, muka air tanah dan keberadaan ruang terbuka. Ketiga, penyusunan Model Pengelolaan RTH sebagai Daerah Resapan di wilayah DKI Jakarta dengan mempertimbangkan pasokan PAM, potensi air tanah dari situ atau waduk. Keempat, penyusunan strategi kecukupan air tanah yang diperlukan dalam pengelolaan RTH sebagai daerah resapan air 
untuk memaksimumkan resapan air. Kelima, perumusan arahan kebijakan pengelolaan RTH sebagai daerah resapan air di wilayah DKI Jakarta berdasarkan model dan skenario yang terpilih. Hasil penelitian menunjukkan luas RTH pada tahun 2006 sebesar 24,68 persen, dengan kecukupan sekitar $75 \%$ dari kebutuhan air tanah domestik. Hanya terdapat dua wilayah yang memenuhi syarat luas minimum RTH 30\%, sesuai undang-undang, dengan kecukupan melebihi kebutuhan air tanah domestik yaitu Jakarta Selatan dan Jakarta Timur. Model dinamik pengelolaan RTH sebagai daerah resapan menunjukkan ada berbagai model, ada yang kelebihan, ada yang kekurangan. Contohnya, terdapat 2 wilayah yang memiliki kelebihan pasokan air tanah domestik yang dapat menjadi pemasok bagi wilayah lain, yaitu Jakarta Selatan dan Jakarta Timur, dan ada yang wilayah yang memiliki kelebihan pasokan air tanah domestik tetapi tidak dapat digunakan untuk memasok wilayah lain, yaitu Jakarta Utara, dan adaa daerah yang hanya sebagaai penerima pasokan dari wilayah lain, yaitu Jakarta Pusat dan Jakarta Barat. Berkaitan dengan skenario pengelolaan RTH dalam rangka memenuhi kebutuhan air tanah domestik, ada 5 skenario. Lima scenario itu antara lain skenario pertama, luas RTH seperti luas RTH tahun 2006 dan pasokan situ atau waduk tahun 2006. Skenario kedua, pasokan kebutuhan air domestik penduduk hanya dari PAM saja. Tiga skenario lainnya merupakan perpaduan skenario-skenario yang ada. Berdasarkan skenario-skenario yang disusun kemudian ditentukan satu skenario. Satu skenario itu adalah wilayah DKI Jakarta sampai dengan tahun 2016 harus dipenuhi dari luas RTH tahun 2006 (16.028,05 ha), penambahan RTH tambahan pada tahun 2007 sampai dengan 2016 sebesar 152,49 ha, pasokan situ tahun 2006, pasokan PAM dan untuk beberapa wilayah harus dipenuhi dari pasokan air tanah dari wilayah lain.

4. Eusuff, Muzaffar M ; Lansey, Kevin E. (2004) menyajikan permasalahan penggunaan resapan air untuk menjaga keberlanjutan ketersediaan air bersih. Tujuan dari penggunaan fasilitas resapan adalah agar sumber daya air tanah yang tersedia terjaga dengan cara menyimpan air untuk masa depan. Air reklamasi yang dihasilkan digunakan terutama untuk air bersih, tetapi bukan untuk air minum. Perbaikan kualitas air selama infiltrasi dan transportasi air tanah yang signifikan dan secara kolektif disebut sebagai usaha menormalkan tanah-akuifer atau soilaquifer treatment (SAT). Operasional resapan dikelola secara efisien mempertimbangkan kekhawatiran moneter, kualitas air dan lingkungan. Dalam tulisan ini menggunakan model manajemen SAT. Dalam model manajemen SAT, menggunakan SCE. SCE adalah teknik meta-heuristik, pencarian yang relatif baru untuk masalah-masalah yang berlanjut yang telah digunakan secara luas 
untuk kalibrasi model hidrologi. Dalam aplikasi ini, SCE terintegrasi dengan model simulasi (MODFLOW, MT3D, dan MODPATH) untuk mewakili gerakan dan transformasi kualitas.

5. Menurut J.Y.Lee (2010), di Korea, air tanah telah banyak dieksploitasi dengan cara yang tidak baik, atau lebih tepatnya ceroboh. Penggunaan air tanah tahunan terus mengalami peningkatan. Pada tahun 1994 volume air tanah yang digunakan mencapai 2,57 miliar $\mathrm{m}^{3}$ dan pada tahun 2007 menjadi 3.72 milyar $\mathrm{m}^{3}$. Sebanyak 48,1\% dikonsumsi untuk keperluan rumah tangga. Oleh karena buruknya pengembangan dan manajemen, Korea telah dihadapkan beberapa masalah tanah kritis, termasuk tingkat penurunan volume air dan kualitas kerusakan yang disebabkan oleh pencemaraan hidrokarbon minyak bumi. Dalam penelitian itu dikemukakan bahwa $62 \%$ sumur air tanah menunjukkan penurunan permukaan aair tanah selama periode 2004-2008. Pencemaran air tanah oleh hidrokarbon minyak bumi terdeteksi pada pangkalan militer dan fasilitas umum, yang menarik perhatian nasional. Hal lain yang meresahkan masyarakat adalah adanya radiasi nuklir seperti uranium dan radon dalam air tanah yang menimbulkan kekhawatiran kesehatan masyarakat. Hal temuan lainnya, adanya trichloroethylene (TCE), telah sering ditemukan dalam air tanah perkotaan dan industri. Akibatnya, terkait isu lingkungan telah memaksa pemerintah dan pihak berwenang terkait untuk segera menyusun rencana mitigasi untuk mengamankan masa depan yang berkelanjutan tentang penggunaan sumber daya air tanah.

6. Getchell dan Wiley (1995), mengamati di banyak wilayah di Amerika Serikat, teknik peresapan buatan muncul sebagai solusi yang efektif untuk mempertahankan atau meningkatkan kapasitas akuifer. Dalam kondisi alami, akuifer terutama diisi oleh infiltrasi curah hujan, melalui badan-badan air permukaan dan akuifer dari wilayah lain. Pertumbuhan penduduk dan perkembangan lahan yang menyertainya di banyak negara bagian itu telah menurunkan jumlah daerah terbuka yang tersedia untuk proses infiltrasi alami. Di beberapa wilayah, fluktuasi musiman dalam penyediaan air dan kebutuhannya menjadi masalah. Kebanyakan diatasi dengan pengambilan air tanah dengan cara memompa air tanah, melalui sumur. Dalam jangka panjang perlakuan seperti ini berakibat pada persediaan jumlah air tanah, beserta kualitasnya. Dalam beberapa kasus, sumur mungkin harus dibor lebih dalam, dan manjadi masalah setelah lobang pemboran terhubung dengan sumber kontaminasi alam atau buatan manusia. Dalam kondisi ini, peresapan buatan dapat digunakan di kedua akuifer terkonsolidasi serta akuifer batuan dasar. Ada berbagai teknik peresapan buatan yang digunakan, termasuk aplikasi permukaan, seperti kolam, genangan air sungai yang tidak mengalir, modifikasi rute air 
permukaan, dan sumur injeksi. Metode yang bergantung pada infiltrasi air permukaan ke dalam akuifer umumnya bekerja baik pada akifer dangkal. Masalahnya cara ini memerlukan lahan yang luas. Wilayah yang diperlukan tergantung pada permeabilitas akuifer dan konfigurasi serta volume air yang ditargetkan untuk isi ulang.

7. Herman Bouwer (2002), menyampaikan bahwa peresapan buatan air tanah dapat dengan membuat genangan air pada suatu ledokan, selokan, atau fasilitas lain di mana ada proses infiltrasi dan bergerak ke bawah untuk mengisi ulang akuifer. Peresapan buatan semakin banyak digunakan untuk penyimpanan air bawah tanah jangka pendek maupun jangka panjang, di mana peresapan buatan memiliki beberapa keunggulan dibandingkan penyimpanan permukaan, dan penggunaan kembali air. Peresapan buatan membutuhkan permukaan tanah permeabel. Parit di zona tidak jenuh juga dapat digunakan. Air juga bisa langsung disuntikkan ke dalam akuifer melalui sumur. Untuk merancang sebuah sistem untuk peresapan buatan dari air tanah, infiltrasi tingkat tanah harus ditentukan dan zona tak jenuh antara permukaan tanah dan akuifer harus lebih dulu diketahui permeabilitasnya dan dipastikan tidak adanya daerah tercemar. Masalah kualitas air harus dievaluasi atau diteliti lebih dulu, juga berkenaan dengan penyumbatan lapisan di dasar cekungan yang merupakan permukaan infiltrasi, dan reaksi kimia yang mungkin terjadi dalam akuifer. Bagian dasar dari resapan, terutama sumur resapan buatan, harus dipompa secara periodik untuk membersihkan lapisan penyumbatan.

8. Garth Van Der Kamp dan Masaki Hayashi (1998) ini mengupas mengenai lahan basah sempit yang ada di wilayah semi-arid padang rumput, yang merupakan titik fokus untuk resapan air tanah. Makalah ini memberikan gambaran tentang hidrogeologi dan permeabilitas dari cadangan es di wilayah padang rumput. Oleh karena itu fungsi resapan air tanah dari lahan basah (wetland) adalah suatu pertimbangan penting dalam pengembangan kebijakan konservasi lahan basah. Sebagian besar resapan air tanah dari lahan basah mengalir ke batas lembab dan berfungsi untuk menjaga evapotranspirasi yang tinggi dari vegetasi di wilayah lahan basah. Walau hanya sebagian kecil air mengalir ke wilayah akuifer, tetapi bagian ini penting untuk kelestarian sumber daya air tanah. Drainase lahan basah sangat mungkin menghilangkan sistem aliran lokal, tetapi mungkin memiliki efek kecil pada akuifer. Sejumlah penelitian tentang hidrologi lahan basah yang sempit di daerah agak kering (semi arid) padang rumput utara telah menunjukkan bahwa daerah itu adalah titik fokus dari resapan air tanah. Pada musim dingin sebagian besar air menumpuk dalam bentuk kolam salju. Kolam salju yang akhirnya mencair kemudian mengisi ulang air tanah. Dalam artikel ini ada kutipan dari peneliti 
lain Fuller 1988, Leitch dan Hovde 1996, yang menyatakan bahwa fungsi resapan air tanah lahan basah padang rumput di bagian utara diakui sebagai suatu hal yang bernilai tinggi untuk suatu bentang lahan. Dalam tulisan ini Garth Van Der Kamp dan Masaki Hayashi merujuk pada pendapat Rehm et al. (1982), yang menunjukkan bahwa resapan air tanah juga dapat berasal lahan basah luar, yaitu dari genangan air ephemeral dangkal di dataran tinggi atau dari daerah di mana tanah yang berpasir dan memiliki kapasitas kelembaban rendah. Dalam tulisan ini juga dikemukakan perkiraan tingkat resapan dari tanah basah yang bervariasi dari beberapa peneliti sebelumnya. Contohnya, yaitu Hayashi, 1998, Fortin, 1991, Rehm, 1982, dimana tingkat resapan bervariasi dari $1 \mathrm{~mm}$ hingga $45 \mathrm{~mm}$ per tahun untuk mengisi ulang akuifer.

9. Naik, Pradeep K, et all. (2008) menggambarkan dampak urbanisasi terhadap kondisi air tanah di kota yang sedang berkembang pesat, Solapur, di India tengah. Tulisan ini memberikan penekanan khusus pada pengelolaan air hingga tahun 2020.Tujuannya adalah untuk memberi masukan atau saran kepada pemerintah dalam kaitan dari dampak urbanisasi terhadap lingkungan air tanah. Solapur kota dengan luas 178 $\mathrm{km}^{2}$ mendapat isi ulang air (groundwater recharge) sekitar 24 juta $\mathrm{m}^{3}$ air tanah per tahun dari berbagai sumber. Pengurangan daerah resapan, yang biasanya karena akibat dampak urbanisasi, terus terjadi. Sebaliknya, ada peningkatan kebutuhan jumlah air oleh karena penambahan jumlah penduduk. Dibandingkan dengan pertengahan 1970-an, terjadi kenaikan permukaan air tanah dalam wilayah pusat kota, karena ada program pengisian ulang airtanah (groundwater recharge), dan pembatasan pengambilan air bawah tanah. Sebaliknya di luar wilayah kota, ada penurunan permukaan air tanah akibat pemanfaatan air tanah untuk keperluan irigasi. Demikian pula berkaitan dengan kualitas air tanah. Penurunan kualitas air tanah telah dapat dilokalisasi. Kualitas air yang memburuk selama 10 tahun terakhir, khususnya di dalam sumur, terutama karena salah metode pembangunannya. Walaupun demikian secara umum dibandingkan kualitas air tahun 1970an, maka kualitas air hasil penelitian terbaru tidak mengalami perubahan berarti.

10. Foulquier, Arnaud et all, (2011) meneliti tentang pengelolaan resapan air tanah buatan atau Artificial Groundwater Recharge (AGR) kaitannya dengan karbon organik terlarut atau Dissolved Organic Carbon (DOC). Sistem yang sangat bergantung pada tanah dengan kapasitas dan zona tak jenuh untuk mempertahankan jumlah materi organik yang dihasilkan selama terjadinya hujan pada daerah perkotaan. Namun, karbon organik terlarut (DOC) terjadi penurunan. Penelitian ini menguji perubahan biofilm aktivitas sedimen dalam kaitannya dengan 
pasokan DOC. Hasilnya biofilm secara signifikan lebih berlimpah dan aktif di bawah resapan air tanah buatan (AGR).

11. Eugenio Sanz Perez (1997) meneliti tentang model perkiraan tingkat resapan air tanah di wilayah karst. Beberapa metode tentang perkiraan tingkat resapan air tanah antara lain ada yang menggunakan analisis debit mata air. Metode lainnya, groundwater recharge $(\mathrm{R})$ juga dapat diperkirakan dari curah hujan $(\mathrm{P})$ dan suhu udara $(\mathrm{T})$ dengan rumus $\mathrm{R}=\mathrm{aP}-\mathrm{bT}+\mathrm{c}$. Komponen $\mathrm{a}, \mathrm{b}$, dan $\mathrm{c}$ berasal dari data empat akuifer di zona Mediterania. Dua akuifer, pengisian ulang dihitung dengan mengintegrasikan debit mata air antara dua titik dengan aliran yang sama. Untuk akuifer ketiga, perhitungan yang lebih rumit didasarkan pada akuifer berganda dengan kertas semilog. Sebuah model numerik, SIMERO, digunakan untuk keempat. Mengingat koefisien korelasi yang tepat, prosedur ini menguntungkan karena kesederhanaannya.

12. Bernard T. Nolan, et all. (2007) meneliti tentang resapan air tanah, memperkirakan besarnya resapan air tanah. Metode yang digunakan dengan metode Darcy metode pelacakan (tracer) Chlor dan dibandingkan dengan analisis statistik. Perkiraan resapan berdasarkan pada metode neraca zone jenuh dengan zone tak jenuh Chlor. Umumnya resapan adalah lebih besar pada akuifer dataran pantai, batuan kristal yang remah, batuan karbonat, atau wilayah dengan banyak kandungan pasirnya. Wilayah penelitian yang berada di bagian barat Amerika merupakan wilayah yang resapan airnya rendah, curah hujan kecil, dan tanahnya yang relatif berlempung. Model statistik non linear regresion (NLR) dapat mensimulasikan besar peresapan air, bergantung pada faktor infiltrasi. Model menunjukkan rerata limpasan (run-off) tahunan, suhu udara, curah hujan, indeks eksfiltrasi berpengaruh terhadap besarnya resapan. Karakteristik tanah dan penggunaan lahan kurang berpengaruh terhadap perkiraan besar resapan.

13. Markus, Michael R; et all (1995) mengulas tentang proyek pembangunan resapan buatan di salah satu distrik yang ada di Negara bagian Kalifornia Amerika Serikat. Di wilayah Orange County, California peresapan buatan air tanah telah menjadi kebutuhan masyarakat setempat. Kebutuhan air semakin besar, sehingga resapan alami tidak cukup untuk memenuhi kebutuhan air. Daerah Orange County ini merupakan bagian dari dataran pesisir semi-kering (semi-arid) dengan curah hujan setiap tahun kurang dari 20 inchi atau sekitar $500 \mathrm{~mm}$. Di Distrik Orange County Water telah dibangun peresapan buatan untuk memasok 70 persen kebutuhan air untuk penduduk lebih dari dua juta jiwa. Pemerintah setempat telah memperluas kemampuan mengisi ulang (recharge) dengan Proyek Dam Karet Tahan Api Sungai Santa Ana (the Santa Ana River Inflatable Rubber Dam Project). Dam atau bendungan dibangun setinggi 2,1 meter sepanjang 97,5 meter 
melintang Sungai Santa Ana. Menurut catatan, proyek ini merupakan proyek yang membuat sistem terbesar di Amerika bagian Utara. Hampir 25 juta meter kubik per tahun air banjir ditangkap untuk mengisi ulang dan akan menyediakan air untuk mencukupi kebutuhan bagi100.000 penduduk . Pada tahun pertama (1993), hampir 17 juta meter kubik air dengan perkiraan nilai sebesar \$ 2 juta. Biaya untuk membangun bendungan dan fasilitas yang terkait mencapai \$ 4,7 juta. Untuk mengisi cadangan air tanah , menggunakan lebih dari 1.500 hektar tanah di sepanjang Sungai Santa Ana untuk dibuat ledokan atau kubangan air untuk perkolasi air tanah. Kubangan-kubangan atau sumur-sumur dibangun di dasar sungai sungai itu sendiri, dan beberapa wilayah di luar alur sungai suatu DAS juga sedang digunakan untuk mengisi ulang. Keseluruhan wilayah di luar alur sungai memiliki volume total lebih dari 33 juta meter kubik.

14. Basagaoglu, Hakan; et all (1999), mengkaji sebuah model pengelolaan yang dikembangkan untuk menentukan kebijakan alokasi air. Sistem ini melibatkan waduk (reservoir) serbaguna, aliran hidrolik terhubung dan akuifer, lahan pertanian, pasokan air, sumur observasi, dan zona resapan buatan. Model meminimalkan penyimpangan dari yang ditetapkan untuk penyimpanan dalam waduk dan sepanjang sungai, sehingga untuk mempertimbangkan kemungkinan untuk penyimpanan kelebihan air di musim hujan dan distribusi dalam periode kering berikutnya. Model manajemen diformulasikan dan diselesaikan untuk langkah-langkah waktu bulanan, yang mencakup kondisi kering dan basah, untuk menentukan pemompaan dari sumur pasokan, tingkat peresapan buatan, pengalihan air dari waduk dan aliran ke wilayah pengguna, penyimpanan di reservoir dan sepanjang sungai. Selain itu, analisis sensitivitas dari rencana manajemen sehubungan dengan penggunaan potensi pasokan air tanah dilakukan untuk menganalisis dampak yang terakhir pada kebijakan operasi.

\section{Penutup}

Banyak penelitian dan pendapat para pakar hampir memiliki konklusi yang sama. Kesamaan simpulan itu adalah bahwa resapan buatan menjadi salah satu alternatif solusi untuk menjaga keseimbangan air tanah dan mengatasi problema air. Dengan resapan air tanah dapat tetap menjaga kedalaman mula air tanah yang relatif stabil, paling tidak dapat mengurangi tingkat kekritisan cadangan air tanah sekaligus mengurangi resiko banjir. Berbagai cara yang dilakukan banyak peneliti di berbagai benua sebaiknya menjadi acuan para penentu kebijakan, dalam hal ini pemerintah untuk secara serius mengikuti pemikiran dan hasil penelitian pentingnya pembangunan resapan air buatan, baik pun berupa sumur resapan, penggenangan wilayah ledok, pembuatan waduk, bahkan penyuntikan air ke dalam akifer tertekan atau air tanah dalam. 


\section{Daftar Referensi}

Alley, William M; Healy, Richard W; LaBaugh, James W; Reilly, dan Thomas E. Flow and storage in groundwater systems Science 296. 5575 (Jun 14, 2002): 1985-90.

Balke, Klaus-dieter dan Zhu, Yan. Natural water purification and water management by artificial groundwater recharge . Journal of Zhejiang University 9.3 (Mar 2008): 221-6.

Basagaoglu, Hakan; Marino, Miguel A. Joint management of surface and ground water supplies ditulis oleh. Ground Water 37. 2 (Mar/Apr 1999): 214-222.

Bernard T. Nolan, Richard W. Healy, Patrick E. Taber, Kimberlie Perkins, dan Kerie J. Hitt, David M. Wolock.Factors infuencing groundwater recharge in the eastern United States Journal of Hydrology (2007) $332,187-205$

Chay Asdak, 2007. Hidrologi dan Pengelolaan Daerah Aliran Sungai. Yogyakarta: Gadjah Mada University Press.

Clark, Jordan F; G Bryant Hudson; M Lee Davisson; Woodside, Greg; Herndon, Roy. Geochemical Imaging of Flow Near an Artificial Recharge Facility, Orange County, California . Ground Water 42. 2 (Mar/Apr 2004): 167-174.

Dwi Dinariana, 2011Model Pengelolaan Ruang Terbuka Hijau Sebagai Daerah Resapan Di Wilayah DKI Jakarta" Bogor Disertasi.IPB.

Eugenio Sanz Perez Estimation of basin-wide recharge rates using spring flow, precipitation, and temperature data, . Ground Water 35.6 (Nov/Dec 1997): 1058-1065

Eusuff, Muzaffar M; Lansey, Kevin E.Optimal Operation of Artificial Groundwater Recharge Systems Considering Water Quality Transformations . Water Resources Management 18. 4 (Aug 2004): 379405.

Foulquier, Arnaud; Mermillod-blondin, Florian; Malard, Florian; Gibert, Janine Response of sediment biofilm to increased dissolved organic carbon supply in groundwater artificially recharged with storm water. Journal of Soils and Sediments 11. 2 (Feb 2011): 382-393.

Getchell, Frank dan Wiley, Dave. Artificial recharge enhances aquifer capacity. Water Engineering \& Management 142. 11 (Nov 1995): 24. 
Harian seputar Indonesia, 28 september 2012. Masyarakat Kota Yogyakarta terancam mengalami krisis air bersih akibat musim kemarau berkepanjangan.

Herman Bouwer Artificial recharge of groundwater: hydrogeology and engineering . Journal: Hydrogeology Journal - HYDROGEOL J , vol. 10, no. 1, pp. 121-142, 2002

Indarto, 2010. Hidrologi, Dasar Teori dan Contoh Aplikasi Model Hidrologi. Jakarta: Bumi Aksara.

J . Y . L E E Environmental issues of groundwater in Korea: implications for sustainable use, Environmental Conservation, / Volume 38 / Issue 01 / March 2011, pp 64-74 Copyright (C Cambridge University Press 2011

Ketut Suharta, I., dkk., 2008. Studi Peresapan Air Hujan Di Kota Denpasar. Denpasar: Universitas Udayana

Kolehmainen, Reija E; Kortelainen, Nina M; Langwaldt, Jörg H; Puhakka, Jaakko A Biodegradation of Natural Organic Matter in LongTerm, Continuous-Flow Experiments Simulating Artificial Ground Water Recharge for Drinking Water Production Journal of Environmental Quality 38. 1 (Jan/Feb 2009): 44-52

Linsley, R.K., Kohler M.A. and Paulus J.L.A. 1972. Water Resources Engineering. New York, McGraw-Hill

Markus, Michael R; Thompson, Curtis A; Ulukaya, Matt. Aquifer recharge enhanced with rubber dam installations, Water Engineering \& Management 142. 1 (Jan 1995): 37.

Masoud Fakharinia, Reza Lalehzari and Mostafa Yaghoobzadeh The Use of Subsurface Barriers in the Sustainable Management of Groundwater Resources . World Applied Sciences Journal 19 (11): 1585 1590, 2012. ISSN 1818-4952. (C) IDOSI Publications, 2012

Munevar, Armin; Marino, Miguel A. Modeling analysis of ground water recharge potential on alluvial fans using limited data, Ground Water 37.5 (Sep/Oct 1999): 649-659.

Naik, Pradeep K; Tambe, Jivesh A; Dehury, Biranchi N; Tiwari, Arun N Impact of urbanization on the groundwater regime in a fast growing city in central India, Environmental Monitoring and Assessment 146. 13 (Nov 2008): 339-73. 
Kiyotoka Mori, Hideo Ishii, Akira Somatani, dan Akira Hatakeyama, 1978. Hidrologi untuk Pengairan, diterjemahkan oleh Taulu, L. dari Manual on Hydrology, Penerbit. PT. Pradnya Paramita, Jakarta.

Nayak, Purna C; Rao, Y R; Satyaji; Sudheer, K P., 2006. Groundwater Level Forecasting in a Shallow Aquifer Using Artificial Neural Network Approach. Water Resources Management 20.1 (Feb 2006): 77-90.

Pliakas, F; Petalas, C; Diamantis, I; Kallioras, A., 2005. Modeling of Groundwater Artificial Recharge by Reactivating an Old Stream Bed, Water Resources Management 19. 3 (Jun 2005): 279-29

Setyawan Purnama, 2010. Hidrologi Air Tanah. Yogyakarta: Kanisius

Seyhan, E. 1975. Fundamentals of Hidrology. Utrecht: Geografisch Instituut der rijks Universiteit.

Strahler, N. Athur, Alan H. 1987. Modern Physical Geography. New York: John Wiley and Sons.

Suyono Sosrodarsono dan Kensaku Takeda, 2006. Hidrologi untuk Pengairan. Jakarta: Pradnya Paramita.

Szucs, Peter; Madarasz, Tamas; Civan, FarukRemediating OverProduced and Contaminated Aquifers by Artificial Recharge from Surface Waters .. Environmental Modeling \& Assessment 14. 4 (Aug 2009): 511-520.

Todd, David Keith, 1980. Groundwater Hydrology. Toronto: John Willey and Son

Van Der Kamp, Garth; dan Hayashi, MasakiThe Groundwater Recharge Function Of Small Wetlands In The Semi-Arid Northern Prairies, Great Plains Research 8.1 (Spring 1998): 39-56.

\section{Unduhan dan Media :}

New York's LaGuardia Airport Flooded , 30102012 (USA Today) diunduh dari http:/ / www.huffingtonpost.com/2012/10/30/new-york-laguardiaairport-flooded_n_2045845.html JFK Joins Newark Airport in Reopening After Sandy's Flood (Bloomberg News)

http:/ / www.businessweek.com/news/2012-10-30/sandy-ravages-airlineschedules-as-toll-rivals-blizzards 
INFORMASI, No. 1, XXXIX, Th. 2013

Republik On Line Keluhan Aktivis Lingkungan: Resapan Air Puncak Terus Berkurang (Sabtu, 26 Januari 2013, 00:12 WIB )

Republik On Line, 6 Nov 2009. Krisis Air Bersih Mengancan: Permukaan air tanah di DIY setiap tahun turun $30 \mathrm{Cm}$.

Tempo Focus, 25 Februari. Koran Jakarta - Banjir Lumpuhkan

Kota Semarang

diunduh dari

http://www.tempo.co/read/fokus/2009/02/08/429/Banjir-

Melumpuhkan-Bandara-Ahmad-Yani

Tribun Jateng, Khotim Batal naik KA, Stasiun Tawang Banjir (24 Feb 2013) 